\title{
13. Do traditional culture and identity promote the wellbeing of Indigenous Australians? Evidence from the 2008 NATSISS
}

\author{
Alfred Michael Dockery
}

This chapter reports results from one of several ongoing avenues of investigation into the relationship between Indigenous Australians' attachment to traditional culture and their socioeconomic outcomes and wellbeing. In an analysis of the Australian Bureau of Statistics (ABS) 2002 National Aboriginal and Torres Strait Islander Social Survey (NATSISS), Dockery (2010a) presented evidence that Indigenous people with stronger attachment to their culture fare better on a range of outcomes: self-assessed health, substance abuse, incidence of arrest, employment and educational attainment. Motivating this analysis was an attempt to reconsider the enduring debate between the two predominant and opposing schools of thought on how best to address relations between the Indigenous Australian peoples and what has become 'mainstream' society: self-determination versus assimilation. This has been fought out primarily as a normative debate, with different camps offering their views on what should improve the wellbeing of Indigenous Australians. It is also a debate that has been largely premised on the assumption that elements of traditional Indigenous culture are incompatible with the achievement of socioeconomic outcomes valued in mainstream society. Even those who argue for the right of Indigenous people to maintain traditional culture and lifestyles often present this choice as a trade-off with socioeconomic outcomes valued in the mainstream, but as a legitimate choice for Indigenous people to make.

Contrary to this assumption, evidence from the 2002 NATSISS suggests cultural attachment is instead associated with improved socioeconomic outcomes. Stressing that improving wellbeing should be the objective of Indigenous policy, Dockery (2010a) therefore argued that Indigenous culture should be maintained and leveraged as a part of the solution to Indigenous disadvantage, rather than being seen as part of the problem. However, a number of limitations to that analysis need to be acknowledged, and the role of culture in shaping Indigenous socioeconomic outcomes and wellbeing remains a critically under-researched area. Important among those limitations are the following.

First, no explicit channel though which cultural attachment impacts upon outcomes was specified. As the positive effects of culture seemed to extend 
across a range of life domains, my conjecture is that cultural attachment must impact upon underlying factors intrinsic to wellbeing, such as self-esteem, selfefficacy or self-identity, as possible mechanisms (Dockery 2010a: 330). This lack of a theoretical framework compounds the challenge of 'reverse causality' in the regression results - that it is the achievement of superior socioeconomic outcomes that then leads or empowers people to engage with their culture.

Second, 'culture' or 'cultural attachment' was measured using a single construct derived from factor analysis. In reality, culture is likely to be a multidimensional construct, comprising of a rich tapestry of constituent elements.

Third, there were in fact no direct measures of wellbeing collected in the 2002 NATSISS. The outcome indicators analysed were chosen for their correspondence to widespread media reports of dysfunction in Indigenous communities at the time: poor health, substance abuse, lawlessness, truancy and joblessness. Measuring 'wellbeing' based on mainstream indicators, however, sits uneasily at a conceptual level with the definition of culture adopted, which is based on differences in values and preferences; in much the same way as a tension exists between the spirit of self-determination and the pursuit of statistical equity as implied in the 'Closing the Gap' agenda. What is required is an outcome measure that reflects Indigenous people's own values and preferences. Potentially, measures of 'subjective wellbeing', often based on ratings of life satisfaction or happiness, and in which Indigenous people themselves assess their wellbeing, would meet this criterion. No such measures were collected in the 2002 NATSISS, but a measure of subjective wellbeing and others relating to mental and psychological health are available in the 2008 NATSISS.

In seeking to address these outstanding issues, this paper explores the relationship between culture and subjective wellbeing for Indigenous Australians. The following section provides a brief review of the literature on the links between attachment to traditional indigenous cultures and wellbeing, which comes primarily from other nations in which those cultures are faced with the challenges of persisting alongside a dominant Western economy. The third section then expands on the different elements that appear to capture 'cultural attachment' using a factor analysis of data from the 2008 NATSISS relating to culture. Both the literature review and factor analysis suggest a vital role of selfidentity as a mediator between cultural attachment and subjective wellbeing. This is tested and confirmed in the fourth section, in which the relationships between aspects of cultural attachment and indicators of wellbeing are modeled. The concluding section canvasses some policy implications of the findings. 


\section{Culture and socioeconomic outcomes}

Cultures are, of course, many and varied. At the same time, almost every aspect of human behavior could be deemed to have some cultural dimension to it. At an abstract level, any one definition of culture will never be sufficient for the purposes of all those interested in 'culture'. For an understanding of culture in the context intended here, which relates specifically to indigenous cultures and their persistence within a 'mainstream' culture, a workable definition is that offered by Guiso, Sapienza and Zingales (2006: 2):

... we define culture as those customary beliefs and values that ethnic, religious, and social groups transmit fairly unchanged from generation to generation.

with the added qualification that these beliefs, customs and values are likely to be characterised by unique symbols, text and language that in themselves play a role in distinguishing the group's distinctive identity (Throsby 2001).

A small literature exists in economics relating differences in culture at the individual (micro) level, and societal (macro) level, to social and economic outcomes. In this literature, culture has been largely defined on the basis of nation states, ethnicity or religious denomination. A general deficiency, as highlighted by Guiso, Sapienza and Zingales (2006), is that few studies explicitly state the causal mechanisms through which culture is thought to impact upon outcomes. More often, observed differences in outcomes between countries, races or religious denominations are ex poste labeled as 'cultural' differences. Where attempts have been made to construct cultural explanations for differences in outcomes between groups, these have largely followed the spirit of defining culture in terms of differences in beliefs and preferences (or values). For example, Jews being thought to have a relatively strong preference for education and Confucian values promoting growth and entrepreneurship. For empirical work the testing of a priori hypotheses based on a theory of how culture is thought to impact upon outcomes is clearly preferable to ex poste explanations.

A more detailed consideration of the meaning of culture and reviews of the literature relating culture to economic outcomes can be found in Guiso, Sapienza and Zingales (2006) and Dockery (2010a), and a specific discussion of the relationship between Indigenous culture and educational outcomes in Australia in Dockery (2009). This review does not go over that same ground, and focuses only on how cultural attachment may impact upon outcomes in the context of disadvantaged indigenous populations. The pervading theme of that literature is the importance of culture in strengthening one's sense of self-identity as the main mechanism through which cultural attachment enhances life outcomes, or 
the 'enculturation hypothesis'. According to Wexler (2009: 267), who cites in support a number of studies relating to Indigenous youth in North America, '... studies have consistently found robust correlations between positive affiliation and engagement with their culture and Indigenous young people's wellbeing and resilience'.

Zimmerman et al. (1994) define enculturation as '... the process by which individuals learn about and identify with their traditional ethnic culture' (1994: 199) and '... an affirmation of one's heritage rather than a focus on fitting into the majority culture', which contrasts with acculturation, 'a process by which an ethnic minority assimilates to the majority culture.' (1994: 201). From a factor analysis of a small survey of Native American youth, they identify cultural affinity (pride and interest in traditional culture), family activities and Native American identity as components of enculturation. Some evidence is found that cultural affinity promotes self-esteem; and that cultural identity combined with high self-esteem is a protective factor against alcohol and substance use, while cultural identity combined with low self-esteem is associated with higher risk of alcohol and substance abuse. Whitbeck et al. (2004) also find that enculturation guards against alcoholism among Native American Indians. Enculturation, they argue, provides resilience by preventing individuals from internalising stress associated with historical loss and trauma.

Perhaps the most important evidence on the effect of culture and the critical intermediary role of self-identity comes from the excellent work of developmental psychologist Professor Michael Chandler and colleagues. While Chandler's most relevant work here relates to suicide rates among Canadian youth, the findings suggest a much more general, or intrinsic, role of a sense of persistence of the self in the psychological wellbeing of human kind, indigenous and nonindigenous alike, and has its parallels at the community level (Chandler et al. 2003). A causal mechanism through which cultural attachment is believed to impact upon the outcome is clearly defined, a priori: cultural identification and preservation promotes a strong sense of persistence of self-identity through time, which in turn guards against suicide. This causal link between culture, identity and suicide is well grounded in psychological theory and backed by empirical evidence. In the space available here it is not possible to do justice to this body of research and the philosophy underpinning it. Briefly, it studies the ways in which individuals deal with the paradox of facing inevitable change through time and yet also persisting as the same person through time. Working with Canadian youth, Chandler et al. (2003) classified the strategies young people employ to understand themselves as being the same individual through time. At an individual level, they find a stark inverse relationship between suicide risk and the strength or sophistication of young peoples' understanding of their self-persistence. 
When they began working with Canadian Aboriginal youth, for whom suicide rates are far higher, they found the same result, albeit with Aboriginal youth adopting different 'narrative' interpretations of their persistence as the same person through time. They argue that suicide rates are higher among Aboriginal youth because they are at greater risk of losing '... the thread that tethers together their past, present and future ...' (Chandler et al. 2003: 2) and of losing a sense of control over their future outcomes. Indigenous cultures in Canada, as elsewhere, have suffered the undermining of their cultural norms and values, face an uncertain future and have lost empowerment over that future. As Chandler et al. (2003: 63) hypothesise '...continuity problems that work to undermine commitments to the future at all of these levels are jointly at work, not just in the lives of individual young persons but at the level of whole cultures.'

This hypothesis is borne out by evidence at the community level. While youth suicide rates are markedly higher for Indigenous youth, there is also considerable variation in youth suicide rates between Aboriginal communities in British Columbia; indeed many communities had very low rates or no youth suicides recorded in the period analysed. Those communities for which there is evidence of greater commitment to cultural continuity - in preserving a shared past and creating a collective future - are found to have significantly lower rates of youth suicide. The clear implication is that cultural continuity at the community level helps the young members of that community to develop a stronger sense of persistence of their self identity through time. Viewed another way, cultural continuity at the community level helps to safeguard against young people losing their own sense of self persistence. In later work, Hallett, Chandler and Lalonde (2007) find that the proportion of people who are fluent in an Indigenous language is a strong marker of cultural persistence within communities and strong predictor of youth suicide rates.

In addition to guarding against suicide, the importance of a strong sense of persistence of self-identity is likely to apply to other activities representing 'investments' in the future, such as education, health, a career, relationships with family and community; and the impact of losing that sense of self continuity is likely to transcend into adulthood. Chandler et al. (2003: 50) speak of the '... expectation that young people who somehow lose the thread of their own and others' personal continuity in time will also behave in ways that show a lack of appropriate care and concern for their own future well-being'. Indeed, they are now collecting data on other indicators that they expect to be sensitive to cultural continuity, nominating school completion rates and academic achievement as two such variables.

Relatively few studies have specifically explored the links between culture and subjective wellbeing. These also generally take the view that attachment to, or identification with, a particular culture can be a source of enhancement of 
wellbeing for minority and indigenous peoples (see Akerlof and Kranton 2010; as well as Ratzlaff et al. 2000; Suh 2000; and other contributions in Diener and Suh 2000). However, Ratzlaff et al.'s (2000: 55) findings also point to the possibility that identification with minority cultures can lead to 'cultural inconsistencies' in values, and some coping strategies that individuals adopt to deal with these inconsistencies can result in reduced subjective wellbeing.

\section{Defining and measuring culture}

As noted, Dockery (2010a) relied on a factor analysis of selected questions relating to culture contained in the 2002 NATSISS. A single measure was generated from the dominant factor, potentially overlooking the fact that culture is a rich concept and likely to be multi-dimensional. To explore the additional dimensions of culture, factor analysis was applied to data from questions contained in the language and culture section of the 2008 NATSISS, with the analysis restricted to persons aged 15 and over. Not all the items relating to culture in the 2008 NATSISS are the same as those contained in the 2002 data. Some significant new questions asked are the frequency with which individuals attend cultural events and the importance they attach to attending cultural events. Appendix 13A Table 13A.1 presents the list of variables included in the factor analysis along with their weighted mean value. As with the 2002 data, there is one dominant factor with a high Eigenvalue. However three other factors returned Eigenvalues of greater than 1 and, following that rule of thumb, these are retained for analysis (see Table 13.1).

The loadings in the rotated coefficient matrix provide four readily interpretable factors, or elements of cultural attachment - henceforth termed participation, identification, language and traditional economic activities (or just 'traditional activities'). Two points to note are that each individual element fits comfortably within our definition of 'culture' as relating to unique values and preferences of Indigenous Australians that may be characterised by unique symbols, text or language. Second, the identity factor - which is most strongly associated with recognising homelands, identifying with a clan, tribal or language group, and how important it is to the individual to attend cultural events - is clearly a close parallel to the concept of self-identity described in the literature as being important to Indigenous wellbeing, and to wellbeing more broadly. 
Table 13.1 Rotated factor pattern, cultural variables, Indigenous Australia, $2008^{a}$

\begin{tabular}{|c|c|c|c|c|}
\hline Cultural dimension $^{\mathrm{b}}$ & $\begin{array}{c}\text { Factor } 1 \\
\text { Participation }\end{array}$ & $\begin{array}{l}\text { Factor } 2 \\
\text { Identity }\end{array}$ & $\begin{array}{l}\text { Factor } 3 \\
\text { Language }\end{array}$ & $\begin{array}{c}\text { Factor } 4 \\
\text { Traditional } \\
\text { activities }\end{array}$ \\
\hline Cultural events attended: festival & 0.687 & 0.184 & 0.035 & 0.045 \\
\hline $\begin{array}{l}\text { Participated in cult. activities: story } \\
\text { telling }\end{array}$ & 0.638 & 0.121 & 0.139 & 0.155 \\
\hline $\begin{array}{l}\text { Participated in cult. activities: } \\
\text { performance }\end{array}$ & 0.629 & -0.007 & 0.209 & 0.126 \\
\hline $\begin{array}{l}\text { Cultural events attended: Aboriginal } \\
\text { organisation }\end{array}$ & 0.628 & 0.284 & -0.159 & -0.049 \\
\hline Participated in cult. activities: art/craft & 0.625 & 0.104 & 0.044 & 0.131 \\
\hline Cultural events attended: ceremonies & 0.542 & 0.147 & 0.367 & 0.103 \\
\hline Cultural events attended: NAIDOC week & 0.489 & 0.437 & -0.252 & -0.078 \\
\hline $\begin{array}{l}\text { Recognises homelands or traditional } \\
\text { country }\end{array}$ & 0.037 & 0.784 & 0.145 & 0.081 \\
\hline $\begin{array}{l}\text { Identifies with clan, tribal or language } \\
\text { group }\end{array}$ & 0.159 & 0.765 & 0.199 & 0.026 \\
\hline Importance of attending cult. events & 0.363 & 0.640 & 0.098 & 0.221 \\
\hline How often attends cult. events & 0.408 & 0.510 & 0.094 & 0.398 \\
\hline Speaks an Indigenous language at home & 0.048 & 0.118 & 0.884 & 0.075 \\
\hline Speaks an Indigenous language & 0.134 & 0.197 & 0.847 & 0.122 \\
\hline Participated in cult. activities: fish & 0.038 & 0.101 & -0.090 & 0.839 \\
\hline Participated in cult. activities: hunt & 0.119 & 0.117 & 0.400 & 0.691 \\
\hline Participated in cult. activities: gathering & 0.417 & 0.058 & 0.330 & 0.507 \\
\hline Eigenvalue & 5.048 & 1.896 & 1.257 & 1.127 \\
\hline
\end{tabular}

a. Derived using SAS Factor Procedure with the principal components and varimax rotation options. Based on responses from 7823 Indigenous persons aged 15 and over.

b. Questions on attendance at cultural events and participation in cultural activities relate to the past 12 months.

NAIDOC $=$ National Aborigines and Islanders Day Observance Committee

Source: Author's customised calculations using the 2008 NATSISS, accessed using the Remote Access Data Laboratory (RADL)

To empirically explore the associations between these dimensions of cultural attachment and wellbeing, the standardised scoring coefficients generated from the factor analysis are used to calculate a score for each individual on each of these four dimensions. However, previous research has indicated that the effect of cultural attachment may vary according to context. Specifically, the impact of culture may vary according to whether the individual lives in remote or non-remote areas and, just as significantly, outcome measures may also vary by remoteness. Most obviously, Indigenous Australians living in very remote areas are likely to face lower employment opportunity and have limited 
access to services in areas such as health and education. Further, the effects of cultural attachment upon outcome variables may not be linear. Dockery (2010a) hypothesised that Indigenous people with low cultural attachment and those with high cultural attachment may experience better outcomes than those with intermediate levels of cultural attachment.

To compare cultural engagement between Indigenous people living in remote and non-remote areas, each factor is standardised to have a mean of zero and standard deviation of 1 . Table 13.2 shows that, as expected, cultural attachment varies substantially between the two populations. While there are no significant differences in the remote and non-remote factor scores for participation, those in remote areas have, on average, significantly higher scores in terms of identification, language and engagement in traditional activities. Given this variation, coupled with likely variation in outcomes by remoteness, a major limitation of the 2008 NATSISS confidentialised unit record file (CURF) is that remoteness is categorised into two only levels. In contrast, the initial release of the CURF for the 2002 NATSISS allowed separate identification of those in major cities, inner regional areas, outer regional areas and those in remote/very remote areas. Including Indigenous persons residing in major cities along with those residing in outer regional areas in the one category is most certain to be problematic, though it is possible to further differentiate by geography within some States.

Table 13.2 Standardised cultural factor scores: Mean score for Indigenous people in remote and non-remote areas, Indigenous Australia, 2008

\begin{tabular}{|l|r|r|r|}
\hline Cultural factor & \multicolumn{1}{c}{ Mean Non-remote } & \multicolumn{1}{c|}{ Mean Remote } & $\begin{array}{r}\text { T-test (remote v. } \\
\text { non-remote) }\end{array}$ \\
\hline Participation & -0.03 & -0.02 & $\mathrm{p}=0.71$ \\
Identity & -0.15 & 0.24 & $\mathrm{p}<0.0001$ \\
Language & -0.37 & 0.80 & $\mathrm{p}<0.0001$ \\
Traditional activities & -0.13 & 0.39 & $\mathrm{p}<0.0001$ \\
Observations & 5188 & 2635 & \\
\hline
\end{tabular}

a. The mean is calculated using ABS-provided person weights.

Source: Author's customised calculations using the 2008 NATSISS (accessed using the RADL)

In relation to each of these factors, individuals were categorised as having strong, moderate, weak or minimal cultural attachment depending upon the quartile of their factor score. The quartiles are specific to their geography so that, for example, an Indigenous person living in a non-remote area would be classified as having 'strong' identity if their factor score is in the top 25 per cent of people living in non-remote areas. Four dummy variables are generated for each factor to allow for non-linear effects in the modeling. 


\section{The effect of culture on wellbeing: Empirical estimates}

The most straight forward measure of subjective wellbeing available in the 2008 NATSISS comes from a question 'In the last four weeks, how often have you been a happy person?', to which respondents could choose from a set of five options: 'all of the time', 'most of the time', 'some of the time', 'a little of the time' or 'none of the time'. There are however, a range of other indicators of potential interest, including the items making up the Kessler 5-item scale of psychological stress and questions that contribute to the SF-36 measures of mental health and vitality.

To assess the relationship between elements of cultural attachment and wellbeing, multivariate regression models are estimated, with dummy variables representing the quartiles of the cultural factor scores included among the explanatory variables. The number of other explanatory variables is restricted to those that can reasonably be considered 'exogenous' to the relationship being studied between culture and the outcome variable: gender, age, remoteness, marital status, and having experienced removal of, or from, natural families. This is because the main interest is in the 'gross' relationship between culture and the dependent variables, not the residual effect after controlling for potentially mediating variables. As an example, one could include financial prosperity as an explanatory variable, but to the extent that cultural attachment may influence financial prosperity, we want this full effect to be captured in the coefficients on the cultural variables. The analysis of such transmission pathways is left as a matter for future investigation.

Before discussing the results for subjective wellbeing, it is of interest to check if the findings of positive effects of culture on 'mainstream' indicators based on the 2002 NATSISS data (Dockery 2010a) are confirmed by the 2008 data. Results for models estimating the probability of reporting good or very good health, of having completed high school, of being employed, of ever having been formally charged by police and of having consumed a level of alcohol deemed to be risky in the past two weeks are presented in Appendix 13A Table A13.2. For simplicity, these are all specified as binary logit models and the odds ratios reported. Hence, for example, the odds ratio of 1.27 for being married in the model of self-assessed health indicates that married persons are 27 per cent more likely to report being in good health, while the odds ratio of 0.76 in the model for having been charged indicates married persons are 24 per cent less likely to have been charged by police. 
The broad picture confirms the previous findings that Indigenous peoples' stronger attachment to, or engagement with, their traditional culture is associated with more favourable socioeconomic outcomes. It is now possible to also look at the different dimensions of cultural attachment and, consistent with the international literature, a significant independent role of cultural identity is apparent in some models. Positive associations are most apparent with participation in cultural events and activities. This is to be expected as this association is most likely to arise due to either reverse causation or omitted variable bias; that is, those with more positive social economic outcomes are already more inclined to engage in their culture. While it could not be claimed that the estimates for the cultural identity factor are completely unaffected by such endogeneity, it can certainly be argued that they are not as susceptible to this challenge. The two main contributing items of recognising homelands or traditional country, and identifying with a clan or language group, can be expected to be relatively permanent traits rather than ones that fluctuate with health status, labour force status or other outcomes. These results suggest that stronger cultural identity is associated with higher educational attainment and a higher probability of being employed. Speaking an Indigenous language is associated with markedly superior health, and a lower likelihood of abusing alcohol or of being charged, but appears to create barriers to employment. The positive association between speaking Indigenous languages and health may relate to the effectiveness of intergenerational communication of traditional knowledge and values associated with health. Participation in traditional economic activities is the one cultural dimension that seems to be associated with inferior outcomes, notably in terms of education and the chances of being arrested or risky consumption of alcohol.

To reiterate, because of the coarse classification of geographical location into only remote and non-remote, these positive associations with traditional culture can confidently be expected to be understated (and the negative associations overstated). Another important, if unsurprising point to take from these results is the legacy of policies of forced removal of Indigenous children from their natural families. The definition for removal from natural family applied is all those who were themselves removed, or who had parents, grandparents/greatgrandparents or siblings separated from their natural families. Although no significant impact on educational attainment is observed, those from the Stolen Generation, defined in this way, are around 50 per cent more likely to have been charged by police, 30 per cent less likely to report being in good health, 15 per cent more likely to consume alcohol at risky levels and 10 per cent less likely to be employed. 
13. Do traditional culture and identity promote the wellbeing of Indigenous Australians?

Table 13.3 Wellbeing indicators: Regression results, Indigenous Australia, 2008

\begin{tabular}{|c|c|c|c|c|c|c|}
\hline \multirow[t]{2}{*}{ Parameter } & \multicolumn{2}{|c|}{$\begin{array}{l}\text { Often been happy? } \\
\text { (ordered probit) }\end{array}$} & \multicolumn{2}{|c|}{$\begin{array}{l}\text { Mental health } \\
\text { (OLS) }\end{array}$} & \multicolumn{2}{|c|}{$\begin{array}{l}\text { Psychological stress } \\
\text { (logit model) }\end{array}$} \\
\hline & Coeff. & Sign. & Coeff. & Sign. & Odds ratio & Sign. \\
\hline Intercept $\mathrm{t}^{\mathrm{a}}$ & & & 12.83 & $* * *$ & n.a. & \\
\hline Remote & 0.38 & $* * *$ & 1.37 & $* * *$ & 0.98 & \\
\hline Male & 0.07 & $* * *$ & 0.67 & $* * *$ & 0.65 & *** \\
\hline Married & 0.11 & $* * *$ & 0.36 & $* * *$ & 0.74 & $* * *$ \\
\hline Age: $15-19$ years & 0.17 & $* * *$ & 0.96 & $* * *$ & 0.86 & $*$ \\
\hline $20-24$ years & 0.12 & $* *$ & 0.38 & $* * *$ & 1.05 & \\
\hline $25-34$ years & - & & - & & - & \\
\hline $35-44$ years & -0.05 & & -0.30 & ** & 1.04 & \\
\hline $45-54$ years & -0.11 & $* * *$ & -0.64 & $* * *$ & 1.09 & \\
\hline $55-59$ years & -0.05 & & -0.77 & $* * *$ & 1.05 & \\
\hline $60-64$ years & 0.07 & & -0.52 & ** & 0.83 & \\
\hline 65 years and over & 0.23 & $* * *$ & -0.17 & & 0.48 & $* * *$ \\
\hline $\begin{array}{l}\text { Removal from natural } \\
\text { family }\end{array}$ & -0.15 & $* * *$ & -0.57 & $* * *$ & 1.38 & $* * *$ \\
\hline $\begin{array}{l}\text { Cultural participation: } \\
\text { Strong }\end{array}$ & 0.07 & ** & 0.34 & $* * *$ & 0.97 & \\
\hline Moderate & 0.07 & $*$ & 0.25 & $* *$ & 0.80 & $* * *$ \\
\hline Weak & -0.02 & & 0.00 & & 0.92 & \\
\hline Minimal & - & & - & & - & \\
\hline $\begin{array}{l}\text { Cultural Identity: } \\
\text { Strong }\end{array}$ & 0.13 & $* * *$ & 0.57 & $* * *$ & 1.14 & \\
\hline Moderate & 0.06 & & 0.30 & $* *$ & 1.11 & \\
\hline Weak & 0.03 & & 0.12 & & 1.24 & $* * *$ \\
\hline Minimal & - & & - & & - & \\
\hline $\begin{array}{l}\text { Language } \\
\text { Strong }\end{array}$ & 0.12 & $* * *$ & 0.41 & $* * *$ & 1.14 & $*$ \\
\hline Moderate & 0.02 & & 0.18 & & 1.11 & \\
\hline Weak & 0.04 & & 0.19 & & 0.95 & \\
\hline Minimal & - & & - & & - & \\
\hline $\begin{array}{l}\text { Traditional activities: } \\
\text { Strong }\end{array}$ & 0.10 & $* * *$ & 0.43 & $* * *$ & 1.10 & \\
\hline Moderate & 0.01 & & 0.10 & & 1.18 & ** \\
\hline Weak & 0.00 & & 0.04 & & 1.14 & $*$ \\
\hline Minimal & - & & - & & - & \\
\hline Observations & 7538 & & 7524 & & 7523 & \\
\hline Likelihood ratio & & & & & 233 & $* * *$ \\
\hline Adjusted R-sq & & & 0.075 & & & \\
\hline F-test & & & 26.34 & $* * *$ & & \\
\hline
\end{tabular}

a. Four intercept terms for the probit model not reported.

${ }^{* * *},{ }^{* *}$ and ${ }^{*}$ denote significance at the $1 \%, 5 \%$ and $10 \%$ level, respectively.

Source: Author's customised calculations using the 2008 NATSISS (accessed using the RADL) 
Turning now to social and emotional wellbeing, three measures are investigated. One of these, the question on happiness, corresponds well to questions typically asked in the subjective wellbeing literature and, importantly, does solicit the individual's assessment of the extent to which they are leading a happy life. The other indicators investigated are the Kessler scale of psychological stress and the SF-36 items relating to mental health and vitality (of which the happiness question is one). These are constructs which can be expected to correlate with subjective wellbeing, but to my knowledge only a modified version of the Kessler scale has been validated among samples of Indigenous Australians (see Dingwall and Cairney 2010: 25). For the single happiness item, an ordered probit model is fitted which estimates the effect of each variable on the likelihood of the individual reporting they were happy more of the time, so a positive coefficient indicates a movement up the scale ranging from 'none of the time' to 'all of the time'. The happiness item is one of four items used from the SF-36: how often in the past four weeks have you felt calm and peaceful and how often you felt happy contribute to the SF-36 measure of mental health; while how often you felt full of life and had a lot of energy contribute to the SF-36 measure of vitality. Here the four measures are incorporated into a single mental health/vitality measure simply by summing the four items, producing a scale ranging from 1 to 20. A simple linear regression model is fitted so that a positive coefficient indicates that increases in the variable are associated with better mental health. The coefficients appear small, but this variable is tightly clustered, with 60 per cent of the sample scoring between 13 and 18, inclusive. Finally, five items from the Kessler 10 instrument have been included, relating to feelings of nervousness, hopelessness, restlessness, that everything is an effort and sadness. Based on these, a binary variable of high/very high psychological stress and low/moderate psychological stress is provided on the NATSISS CURF. A logit model of the probability of exhibiting high/very high psychological stress is estimated, and the odds ratios presented in the final model reported in Table 13.3.

In general the results conform to expectations drawn from the previous literature. Empirical work has consistently found married people to report higher subjective wellbeing than unmarried persons. Here we find Indigenous people who are married report being happier, have better mental health/ vitality more generally and are markedly less prone to psychological stress. Indigenous people in remote areas are much happier and report better mental health. While this is consistent with some other evidence of better health among Indigenous people in remote areas, Sibthorpe, Anderson and Cunningham (2001) have noted possible measurement bias in self-assessed health reports for Indigenous Australians whose first language is not English, 
and this will most often be the case in remote Australia. Males display slightly greater happiness and general mental health, and are around 35 per cent less likely to be classified as having a high level of psychological stress.

There is strong evidence that the socioeconomic disadvantage of persons of the Stolen Generation has its foundations in the impact of those experiences upon psychological wellbeing. Studies of Native American peoples have associated past policies of forced acculturation and 'ethnic cleansing' with intergenerational trauma similar to that observed among descendents of Holocaust survivors and war veterans, with symptoms such as depression and post-traumatic stress disorder attributed to the genocide of American Indians (Whitbeck et al. 2004: 410). Here it is clear that persons who report having experienced removal themselves or of their direct family are less happy, have lower general mental health and vitality and are 38 per cent more likely to display high psychological stress on the Kessler scale. In each case, the magnitude of these effects is larger than the positive effects of being married as opposed to unmarried, a factor known to have a very substantive effect on psychological wellbeing and its maintenance.

So, what of the effects of culture on wellbeing? There is some evidence of greater participation in cultural events and activities being associated with better mental wellbeing, and to a lesser degree greater happiness, though causation could run either way, or both ways. Engaging in traditional economic activities, such as hunting, fishing and gathering, also promotes wellbeing, but those who score in the middle quartiles on this factor appear to experience greater psychological stress.

The most pronounced effects relate to the identity-dimension of cultural attachment, but the initial picture is somewhat unclear. Strong identification with Indigenous culture is associated with greater regularity of feeling happy and better mental health and vitality more generally. However, having 'weak' cultural identity (relative to minimal) is also associated with more psychological stress. Those with moderate and strong cultural identity are also estimated to experience higher psychological stress than those with minimal identification with their culture, although these effects just fail to gain significance at the $10 \%$ level. The use of Indigenous languages similarly enhances happiness and mental health while simultaneously incurring psychological stress. These results are reminiscent of Trudgen's (2000) vivid account of the stress, confusion and ambiguity experienced by Indigenous people trying to 'live between two cultures', and clinging to a cultural identity and worldview in the face of a dominant culture. However, it is at odds with much of the international findings that a factor measuring strength of cultural identity and knowledge of Indigenous languages should be associated with higher psychological stress. Recall that Chandler (2000) found that a strong sense 
of persistence of self-identity was a critical protective factor against youth suicide, and that the maintenance of traditional languages was an effective marker of such persistence. However, a strong sense of self-identity is not the same thing as a strong sense of persistence of that self-identity through time - those who do strongly identify with Indigenous culture may also suffer psychologically from doubts over the survival of that culture, and what their role would be should their connection with that culture be severed.

To explore this finding further, the models reported in Table 13.3 were estimated separately for the remote and non-remote samples. The positive effects of cultural identity, fluency in Indigenous languages and undertaking traditional economic activities upon happiness and mental health are found to accrue primarily in remote areas. The associations between cultural identity and engagement in traditional activities with greater psychological stress, however, appear to apply only in non-remote contexts. Of course, it is in non-remote areas that Indigenous people will most experience the tensions of living between cultures. A further hypothesis warranting investigation is that Indigenous Australians with a stronger sense of cultural identity experience greater psychological stress because they also experience, or perceive themselves to experience, more discrimination. While detailed data were collected in the 2008 NATSISS on feelings of discrimination, providing many possibilities for further investigation in this area, only a simple question on whether or not the respondent felt discriminated against in the past 12 months is used here.

Evidence of the degree of compromise Indigenous people face when trying to maintain their own cultural identity while coexisting with another, dominant culture can be seen in Fig. 13.1. Overall, 27.6 per cent of Indigenous people reported having experienced discrimination, and this figure was virtually identical in remote and non-remote areas. However, Fig. 13.1 shows these proportions across the quartiles of the cultural identity factor scores. In remote areas, a stronger sense of identity with traditional culture does not lead to any greater experiences of discrimination. In contrast, for Indigenous persons living in non-remote areas, it is clear that feelings of discrimination increase directly with the strength of one's cultural identity. In non-remote areas, those scoring in the top quartile of the cultural identity measure are four times more likely to report having experienced discrimination in the past 12 months than those in the bottom quartile.

Table 13.4 reports the results of models which more formally test the role of perceived discrimination in shaping the relationship between cultural attachment and psychological stress. As the association between cultural identity and psychological stress holds only in non-remote areas, the analysis is restricted to persons in these areas. The model for psychological stress from 
Table 13.3 is reproduced as Model 1 of Table 13.4, but with the sample now restricted to non-remote areas. In the interests of parsimony, the coefficients on demographic background variables are suppressed, but these variables were included in the estimation. Relative to Indigenous people with the lowest level of cultural identity, individuals with strong and moderate cultural identity are estimated to be around 25 per cent more likely to be in high or very high psychological stress (significant at the $10 \%$ level), and those with weak cultural attachment around one-third higher (highly significant).

A simple dummy variable capturing whether or not the respondent felt discriminated against in the past 12 months is then added (Model 2). Experiencing discrimination has a dramatic correlation with psychological stress, with those who experienced feelings of discrimination being twice as likely to be classified as having high or very high levels of psychological stress. It must be stressed that the subjective construction of both these variables means that this relationship must be interpreted with caution other individual effects are likely to impact upon both measures. This variable accounts for much of the observed higher psychological stress for those with stronger cultural identity. There are now no significant differences in the likelihood of psychological stress between those with high or moderate levels of cultural identity when compared to those with minimal cultural identity. It is those in the second bottom quartile on this measure with the highest level of stress. The higher psychological stress associated with stronger cultural identification therefore appears to be a result of those identifying more strongly with Indigenous culture also being more likely to feel they have been victims of discrimination, as was highlighted in Fig. 13.1. This interpretation is consistent with previous findings by Paradies and Cunningham (2009) based on data from the Darwin Region Urban Indigenous Diabeties study. Using a measure to capture Indigenous experiences of racism, Paradies and Cunningham (2009: 562, 567) find that those who identify more strongly with their culture (as indicated by recognition of homelands/traditional country, identification with a clan, tribal or language group or identifying as a member of the Stolen Generation) are not only more likely to report experiences of racism, but are also more likely to report negative emotional reactions in response to those experiences.

In contrast, Whitbeck et al. (2004) find evidence that 'enculturation' provides resilience by preventing individuals from internalising stresses associated with trauma. To test whether a strong sense of cultural identity has a 'protective' effect that mitigates the negative impacts of perceived discrimination, Model 3 includes interaction terms between the identity measures and the discrimination dummy. However, no evidence of a protective effect is found - the estimated effect of experiencing feelings of discrimination is to roughly 
double the chance of being in psychological stress irrespective of the strength of one's cultural identity. In a review of studies of personal strategies for coping with racism, Brondolo et al. (2009) nominate 'racial identity development' as one of three major forms of coping. However, as with the results here, they do not find strong evidence from the empirical literature of identity acting as a buffer against race-related stress (Brondolo et al. 2009: 74).

Fig. 13.1 Proportion of Indigenous people reporting experiencing discrimination in past 12 months, by remoteness and strength of cultural identity, Australia, 2008

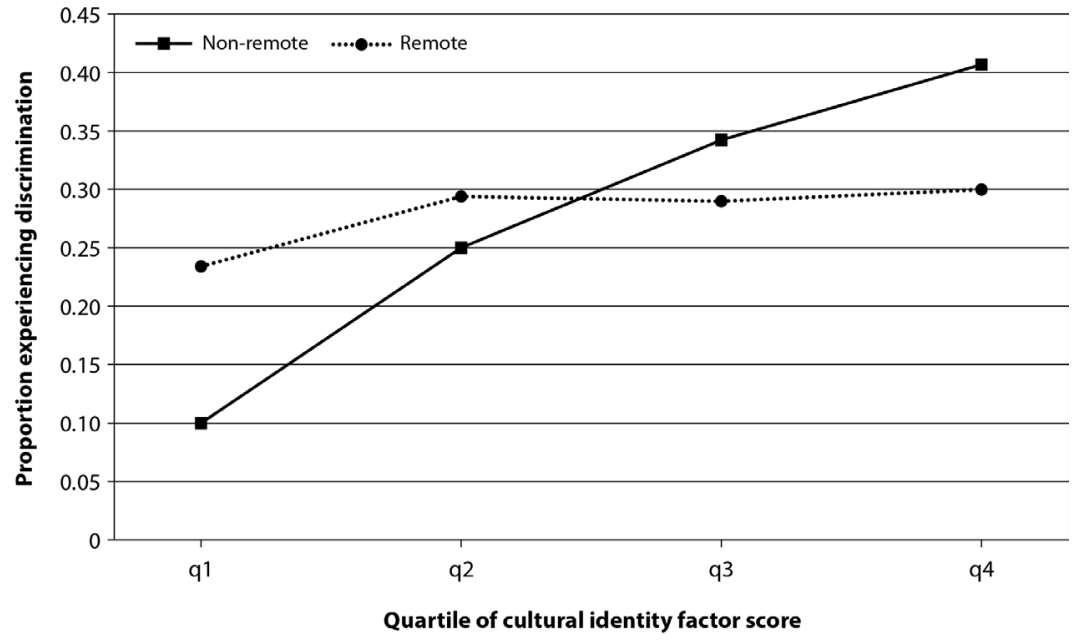

Source: Author's customised calculations using the 2008 NATSISS (accessed using the RADL) 
Table 13.4 Psychological stress: Logistic regression results controlling for discrimination, Indigenous people living in non-remote areas (odds ratios), Indigenous Australia, 2008

\begin{tabular}{|c|c|c|c|c|c|c|}
\hline \multirow[t]{2}{*}{ Parameter $^{\mathrm{a}}$} & \multicolumn{2}{|c|}{ Model 1} & \multicolumn{2}{|c|}{ Model 2} & \multicolumn{2}{|c|}{ Model 3} \\
\hline & $\begin{array}{l}\text { Odds } \\
\text { Ratio }\end{array}$ & Sign. & $\begin{array}{l}\text { Odds } \\
\text { Ratio }\end{array}$ & Sign. & $\begin{array}{l}\text { Odds } \\
\text { Ratio }\end{array}$ & Sign. \\
\hline Removal from natural family & 1.49 & $* * *$ & 1.38 & $* * *$ & 1.38 & $* * *$ \\
\hline $\begin{array}{l}\text { Cultural participation: } \\
\text { Strong }\end{array}$ & 0.90 & & 0.76 & $* * *$ & 0.75 & $* * *$ \\
\hline Moderate & 0.73 & $* * *$ & 0.69 & *** & 0.69 & $* * *$ \\
\hline Weak & 0.87 & & 0.84 & * & 0.84 & * \\
\hline Minimal & - & & - & & - & \\
\hline $\begin{array}{l}\text { Cultural identity: } \\
\text { Strong }\end{array}$ & 1.26 & $* *$ & 1.02 & & 1.01 & \\
\hline Moderate & 1.23 & $* *$ & 1.05 & & 1.05 & \\
\hline Weak & 1.33 & *** & 1.20 & * & 1.20 & * \\
\hline Minimal & - & & - & & - & \\
\hline $\begin{array}{l}\text { Language: } \\
\text { Strong }\end{array}$ & 1.14 & & 1.07 & & 1.07 & \\
\hline Moderate & 1.16 & & 1.14 & & 1.14 & \\
\hline Weak & 0.94 & & 0.93 & & 0.93 & \\
\hline Minimal & - & & - & & - & \\
\hline $\begin{array}{l}\text { Traditional activities: } \\
\text { Strong }\end{array}$ & 1.19 & * & 1.11 & & 1.11 & \\
\hline Moderate & 1.25 & ** & 1.19 & * & 1.19 & $*$ \\
\hline Weak & 1.13 & & 1.11 & & 1.10 & \\
\hline Minimal & - & & - & & - & \\
\hline Felt discrimination in past year & & & 1.98 & $* * *$ & & \\
\hline $\begin{array}{l}\text { Interaction terms: Felt } \\
\text { discrimination and - } \\
\text { Strong cult. identity }\end{array}$ & & & & & 1.99 & $* * *$ \\
\hline Moderate cult. identity & & & & & 2.01 & $* * *$ \\
\hline Weak cult. identity & & & & & 1.97 & $* * *$ \\
\hline Minimal cult. identity & & & & & 1.95 & $* * *$ \\
\hline Observations & 5058 & & 5058 & & 5058 & \\
\hline Likelihood ratio & 207 & $* * *$ & 296 & $* * *$ & 296 & $* * *$ \\
\hline
\end{tabular}

a. Intercept and coefficients for gender, marital status and age not reported.

${ }^{* * *},{ }^{* *}$ and ${ }^{*}$ denote that the odds ratio is significantly different from 1 at the $1 \%, 5 \%$ and $10 \%$ level, respectively.

Source: Author's customised calculations using the 2008 NATSISS (accessed using the RADL) 


\section{Conclusions and implications}

In this chapter I have sought to further our understanding of the importance of traditional culture to Indigenous Australians. It provides evidence on the links between cultural attachment and subjective wellbeing, supplementing evidence relating to objective and mainstream indicators of socioeconomic outcomes. I have also sought to cast light on the causal mechanisms through which cultural attachment affects wellbeing and socioeconomic outcomes, by drawing on relevant overseas literature and empirically expanding on the dimensions of cultural attachment included in the multivariate models.

Strong caveats must always be placed on our ability to unearth causal relationships between variables when working with cross-sectional and self-reported data, such as the 2008 NATSISS. That withstanding, the analysis does offer some added rigour over previous work. Culture, and hence cultural attachment, is clearly defined ex ante, and a refutable hypothesis put forward with respect to the causal mechanism through which cultural attachment impacts upon outcomes. The hypothesis is that cultural attachment is important to identity formation for Indigenous peoples, and a sense of self-identity is in turn important for mental health. The results are broadly consistent with this hypothesis. The factor analysis of cultural variables contained in the NATSISS demonstrates that cultural identity is one distinct element to Indigenous Australians' attachment to, or engagement with, traditional culture, along with participation in cultural events/activities, language use and participation in traditional economic activities. Further, cultural identity has robust associations with wellbeing.

So the picture is far from complete, but one more piece has been added, and it has been brought into a somewhat sharper focus through additional empirical evidence. That evidence suggests that cultural identity enhances mainstream outcomes and is associated with greater subjective wellbeing. The finding that the positive effects of cultural attachment and identity extend to subjective wellbeing is important, as subjective wellbeing reflects Indigenous people's own values and preferences. For Indigenous and non-Indigenous Australians alike, achieving outcomes such as higher income, employment status and home ownership inevitably involve trade-offs. Higher income and occupational status, for example, may come at the expense of quality time with family. The advantage of subjective wellbeing as an outcome measure, in theory, is that it encapsulates all these trade-offs. Indigenous people with stronger cultural identification, who speak Indigenous languages and who partake in traditional economic activities are happy more often than others. Presumably, they feel their lives are better. 
One inconsistent result with these findings is that strong cultural attachment is associated with greater psychological stress, reminiscent of Ratzlaff et al. (2000) observations on 'cultural inconsistencies' experienced by those of minority cultures and their requisite coping strategies. However, this phenomenon can be readily accounted for empirically by the fact that Indigenous Australians with strong cultural identity are more likely to host feelings of victimisation in the form of discrimination. Indigenous people living in non-remote areas, in particular, appear to pay a high price for maintaining a strong sense of identification with their traditional culture. That price is psychological stress brought about by feelings of discrimination, be that discrimination real or perceived. Their counterparts in remote Australia do not face this trade-off between cultural identity and psychological stress, suggesting that difficulties associated with the coexistence within both a traditional, minority culture and a mainstream culture play an important role in generating this stress.

The results for mainstream socioeconomic outcomes and wellbeing indicators are universal in their condemnation of the most extreme application of the assimilation approach, the forced removal of Indigenous children from their natural families. To some this may seem obvious and unnecessary to reiterate. I disagree. It may now be generally accepted that forced removal was not good policy, but it is not just the extremity with which the policy was executed, the inhumanity of forcibly removing children, that was wrong. The whole approach and the assumptions underlying it were wrong. This point is far from accepted, for many Australians still see assimilation as the only solution to Indigenous disadvantage and traditional Indigenous culture as a barrier to progress. As I have argued elsewhere (Dockery and Milsom 2007), this also seemed to be the 'hidden assumption' underlying much of the Australian Government's evaluations of Indigenous employment programs, since no attempts were made to evaluate programs against the stated objectives of cultural preservation, community capacity building or self-determination.

If the empirical results presented here are to be accepted, then the policy implications that follow would seem clear. The objective of policy should be to maximise wellbeing. Attachment to traditional culture and a strong sense of self-identity not only increase the wellbeing of Indigenous Australians, but are also associated with better 'mainstream' socioeconomic outcomes. Surely, then, Indigenous cultures need to be preserved and strengthened, not slowly left - or helped - to die. Perhaps the reason this is not obvious is that non-Indigenous Australians do not derive wellbeing from Indigenous culture; and therefore do not accept this as a 'legitimate' source of wellbeing. And while attachment to traditional culture enhances the wellbeing of Indigenous Australians, this sort of prejudice (or ignorance?) surely contributes to the psychological stress experienced by those trying to maintain their cultural identity. There 
seems no solution to this dilemma - unless, of course, Australians all learn to celebrate and respect the cultures of our first peoples. In the current pursuit of equity between Indigenous and non-Indigenous Australians, increasing nonIndigenous Australians' knowledge, understanding and respect of Indigenous cultures may well be the most important gap to close.

\section{Reflections on the 2008 NATSISS}

Finally, I conclude with some reflections on the data from the 2008 NATSISS for the purposes of this particular analysis and the wider program of research into culture and wellbeing. Some positives and negatives of the most recent CURF have already been flagged. Undoubtedly, the most significant drawback of the 2008 data is the inadequate controls for remoteness. The remote/nonremote dichotomy permitted in the 2008 CURF compares to the four categories of the Australian Standard Geographical Classification of Remoteness available for the 2002 CURF: major cities; inner regional; outer regional; and remote/very remote. This will not only reduce the statistical certainty of estimates for many purposes but, worse, is likely to lead to biased and even spurious findings. As one example, the measure of cultural attachment used in previous work with the 2002 data (Dockery 2009, 2010a) increases with remoteness, while educational attainment decreases with remoteness. Results from regression models without controls for remoteness suggest that educational attainment is negatively associated with cultural attachment, when exactly the reverse is found upon inclusion of controls for the four classifications of remoteness. As so many variables vary systematically with remoteness, the potential for such misleading findings is pervasive with the 2008 data.

On the positive side, the inclusion in the 2008 survey of measures of subjective wellbeing and mental health is perhaps the most significant enhancement over previous surveys, and provides important new research opportunities. There have also been welcome improvements to the cultural variables, including new questions on the importance individuals place on attending cultural events; and on the frequency of attendance and barriers to attending; and on cultural education. These improvements have been achieved while maintaining enough consistency between surveys to enable comparative analysis: had space permitted in this paper a comparison of rates of cultural engagement and Indigenous language use over time would have been most instructive. Finally, a very basic indicator of experiences of discrimination has proven here to have very strong explanatory power. Further analysis of the much richer information on discrimination (such as frequency and situations) and other variables from the expanded Life Experiences module in the 2008 NATSISS is likely to offer valuable insights into the wellbeing of Indigenous Australians. 


\section{Appendix 13A}

Table 13A.1 Cultural variables included in exploratory factor analysis and
weighted means, Indigenous Australia, 2008

Variable $^{\mathrm{a}} \quad$ Mean $^{\mathrm{b}}$

\begin{tabular}{l|l} 
Speaks an Indigenous language at home & 0.11
\end{tabular}

\begin{tabular}{l|l} 
Speaks an Indigenous language & 0.19
\end{tabular}

\begin{tabular}{l|l} 
Identifies with clan, tribal or language group & 0.62
\end{tabular}

\begin{tabular}{l|l} 
Recognises homelands or traditional country & 0.72
\end{tabular}

Cultural events attended in past 12 months:

Ceremonies

0.16

NAIDOC week activities

0.36

Festival or carnival involving arts, craft music or dance

0.23

Involved with ATSI organisation

0.18

Participated in cultural activities:

Fishing

0.45

Hunting

0.22

Gathering wild plants or berries

0.16

ATSI arts or craft

0.17

Performed ATSI music, dance or theatre

0.11

Wrote or told ATSI stories

0.15

Importance of attending cultural events

(1 very important, 2 important, 3 not important, 4 not important at all)

How often attends cultural events

$(1=$ daily to $7=$ less than once per year $)$

a. Unless otherwise stated, all variables are binary $(1=$ yes, $0=$ no $)$ dummies.

b. Means are weighted by the person weight provided by ABS.

NAIDOC $=$ National Aborigines and Islanders Day Observance Committee

ATSI $=$ Aboriginal or Torres Strait Islander

Source: Author's customised calculations using the 2008 NATSISS (accessed using the RADL) 
Table 13A.2 Logistic regression models for 'mainstream' outcomes (odds ratios), Indigenous Australia, 2008

\begin{tabular}{|c|c|c|c|c|c|c|c|c|c|c|}
\hline \multirow{2}{*}{$\begin{array}{l}\text { Variable } \\
\text { Remote }\end{array}$} & \multicolumn{2}{|c|}{$\begin{array}{c}\text { Self- } \\
\text { assessed } \\
\text { Health: } \\
\text { P(healthy) }\end{array}$} & \multicolumn{2}{|c|}{$\begin{array}{l}\text { Education: } \\
\text { P(completed } \\
\text { school) }^{\mathrm{a}}\end{array}$} & \multicolumn{2}{|c|}{ Employed $^{\mathrm{a}}$} & \multicolumn{2}{|c|}{$\begin{array}{c}\text { Ever } \\
\text { charged } \\
\text { by police }\end{array}$} & \multicolumn{2}{|c|}{$\begin{array}{l}\text { Risky alcoho } \\
\text { consumption } \\
\text { in past } 2 \\
\text { weeks }\end{array}$} \\
\hline & 0.96 & & 0.63 & $* * *$ & 1.02 & & 1.12 & $* *$ & 1.07 & \\
\hline Male & 1.34 & $* * *$ & 1.02 & & 2.42 & $* * *$ & 3.71 & $* * *$ & 1.57 & $* * *$ \\
\hline Married & 1.27 & $* * *$ & 1.33 & $* * *$ & 1.78 & *** & 0.76 & $* * *$ & 0.71 & $* * *$ \\
\hline Age: $15-19$ years & 1.78 & $* * *$ & & & & & 0.27 & $* * *$ & 0.45 & $* * *$ \\
\hline $20-24$ years & 1.17 & $*$ & 1.37 & $* * *$ & 0.94 & & 0.70 & $* * *$ & 1.22 & ** \\
\hline $25-34$ years & - & & - & & - & & - & & - & \\
\hline $35-44$ years & 0.63 & $* * *$ & 0.68 & $* * *$ & 1.24 & $* * *$ & 1.12 & & 0.95 & \\
\hline $45-54$ years & 0.44 & $* * *$ & 0.44 & $* * *$ & 1.21 & $* *$ & 0.80 & $* * *$ & 0.57 & $* * *$ \\
\hline $55-59$ years & 0.31 & $* * *$ & 0.25 & *** & 0.67 & $* * *$ & 0.54 & $* * *$ & 0.35 & $* * *$ \\
\hline $60-64$ years & 0.32 & $* * *$ & 0.21 & $* * *$ & 0.32 & $* * *$ & 0.52 & $* * *$ & 0.21 & $* * *$ \\
\hline 65 years and over & 0.32 & $* * *$ & & & & & 0.27 & $* * *$ & 0.08 & $* * *$ \\
\hline Removal from natural family & 0.70 & $* * *$ & 0.92 & & 0.90 & * & 1.55 & $* * *$ & 1.15 & ** \\
\hline \multicolumn{11}{|l|}{ Cultural participation: } \\
\hline Strong & 1.44 & $* * *$ & 2.60 & $* * *$ & 2.09 & $* * *$ & 0.74 & $* * *$ & 0.76 & $* * *$ \\
\hline Moderate & 1.29 & $* * *$ & 1.51 & $* * *$ & 1.54 & $* * *$ & 0.77 & $* * *$ & 0.78 & $* * *$ \\
\hline Weak & 1.16 & $* *$ & 1.20 & * & 1.23 & $* * *$ & 0.87 & * & 0.92 & \\
\hline Minimal & - & & - & & - & & - & & - & \\
\hline \multicolumn{11}{|l|}{ Cultural identity: } \\
\hline Strong & 1.07 & & 1.23 & ** & 1.33 & $* * *$ & 1.11 & & 0.96 & \\
\hline Moderate & 1.09 & & 1.17 & & 1.16 & * & 1.10 & & 1.04 & \\
\hline Weak & 0.93 & & 1.07 & & 1.09 & & 1.16 & * & 0.99 & \\
\hline Minimal & - & & - & & - & & - & & - & \\
\hline \multicolumn{11}{|l|}{ Language: } \\
\hline Strong & 1.24 & $* * *$ & 0.87 & & 0.71 & $* * *$ & 0.98 & & 0.59 & $* * *$ \\
\hline Moderate & 1.09 & & 0.95 & & 0.85 & * & 0.81 & $* * *$ & 0.68 & $* * *$ \\
\hline Weak & 1.14 & * & 1.05 & & 0.90 & & 0.93 & & 0.87 & $*$ \\
\hline Minimal & - & & - & & - & & - & & - & \\
\hline \multicolumn{11}{|l|}{ Traditional activities: } \\
\hline Strong & 1.08 & & 0.79 & $* *$ & 1.08 & & 1.27 & $* * *$ & 1.29 & $* * *$ \\
\hline Moderate & 1.03 & & 0.80 & $* *$ & 1.02 & & 1.29 & $* * *$ & 1.31 & $* * *$ \\
\hline Weak & 1.21 & $* * *$ & 0.87 & & 1.02 & & 1.08 & & 1.02 & \\
\hline Minimal & - & & - & & - & & - & & - & \\
\hline Observations & 7634 & & 6088 & & 6088 & & 7629 & & 5656 & \\
\hline Likelihood ratio & 631 & $* * *$ & 417 & $* * *$ & 627 & $* * *$ & 1111 & $* * *$ & 624 & $* * *$ \\
\hline
\end{tabular}

a. Models for having completed school, and being in employment restricted to persons aged 20-64.

${ }^{* * *},{ }^{* *}$ and * denote that the odds ratios is significantly different from 1 at the $1 \%, 5 \%$ and $10 \%$ level, respectively. 


\section{References}

Akerlof, G. and Kranton, R. 2010. Identity Economics, Princeton University Press, Princeton, New Jersey.

Australian Bureau of Statistics (ABS) 2010. National Aboriginal and Torres Strait Islander Social Survey: Users' Guide, 2008, cat. no. 4720.0, ABS, Canberra.

Brondolo, E., Brady ver Halen, N., Pencille, M., Beatty, D. and Contrada, R. J. 2009. 'Coping with racism: A selective review of the literature and a theoretical and methodological critique', Journal of Behavioral Medicine, 32 (1): $64-88$.

Chandler, M. J. 2000. 'Surviving time: The persistence of identity in this culture and that', Culture \& Psychology, 6 (2): 209-31.

— and Lalonde, C. E. 1998. 'Cultural continuity as a hedge against suicide in Canada's First Nations', Transcultural Psychiatry, 35 (2): 191-219.

—, Lalonde, C. E., Sokol, B. W. and Hallett, D. 2003. 'Personal persistence, identity development, and suicide: A study of Native and non-Native North American adolescents', Monographs of the Society for Research in Child Development, 68 (2): 1-130.

Diener, E. and Suh, E. M. (eds) 2000. Culture and Subjective Well-Being, The MIT Press, Cambridge, Mass.

Dingwall, K. M. and Cairney, S. 2010. 'Psychological and cognitive assessment of Indigenous Australians', Australian \& New Zealand Journal of Psychiatry, 44 (1): 20-30.

Dockery, A. M. 2009. Cultural Dimensions of Indigenous Participation in Education and Training, NCVER Monograph Series 02/2009, National Centre for Vocational Education Research, Adelaide.

2010a. 'Culture and wellbeing: The case of Indigenous Australians', Social Indicators Research, 99 (2): 315-32.

2010b. 'The subjective wellbeing of Indigenous Australians', CLMR Discussion Paper Series 2010/4, Centre for Labour Market Research, Curtin Business School, March.

and Milsom, N. 2007. A Review of Indigenous Employment Programs, National Centre for Vocational Education Research, Adelaide. 
Guiso, L., Sapienza, P. and Zingales, L. 2006. 'Does culture affect economic outcomes?', NBER Working Paper No. 11999, National Bureau of Economic Research, Massachusetts.

Hallett, D., Chandler, M. J. and Lalonde, C. 2007. 'A boriginal language knowledge and youth suicide', Cognitive Development, 22 (3): 392-99.

Paradies, Y. 2005. 'Anti-racism and Indigenous Australians', Analyses of Social Issues and Public Policy, 5 (1): 1-28.

Paradies, Y. and Cunningham, J. 2009. 'Experiences of racism among urban indigenous Australians: Findings from the DRUID study', Ethnic and Racial Studies, 32 (3): 548-73.

Ratzlaff, C., Matsumoto, D., Kouznetsova, N., Raroque, J. and Ray, R. 2000. 'Individual psychological culture and subjective well-being', in E. Diener and E. M. Suh (eds), Culture and Subjective Well-being, MIT Press, Cambridge Mass.

Sibthorpe, B., Anderson, I. and Cunningham, J. 2001. 'Self-assessed health among Indigenous Australians: How valid is a global question?', American Journal of Public Health, 91 (10): 1660-63.

Slater, L. 2010. "“Calling our spirits home" Indigenous cultural festivals and the making of a good life', Cultural Studies Review, 16 (1): 143-54.

Suh, E. M. 2000. 'Self, the hyphen between culture and subjective wellbeing', in E. Diener and E. M. Suh (eds), Culture and Subjective Well-Being, MIT Press, Cambridge Mass.

Throsby, D. 2001. Economics and Culture, Cambridge University Press, Cambridge.

Trudgen, R. 2000. Why Warriors Lay Down and Die, Aboriginal Resource and Development Services Inc., Adelaide.

Ware, J. E. 2004. SF-36 Health Survey Update, viewed 11 October 2011, available at <www.sf-36.org $>$

Wexler, L. 2009. 'The importance of identity, history, and culture in the wellbeing of indigenous youth', Journal of Childhood and Youth, 2 (2): 26776.

Whitbeck, L. B., Chen, X., Hoyt, D. R. and Adams, W. 2004. 'Discrimination, historical loss, and enculturation: Culturally specific risk and resiliency factors for alcohol abuse among American Indians', Journal of Studies on Alcohol, 65 (July): 409-18. 
Zimmerman, M. A., Ramirez, J., Washienko, K. M., Walter, B. and Dyer, S. 1994. 'Enculturation hypothesis: Exploring direct and positive effects among native American youth', in H. L. McCubbin, E. A. Thompson, A. L. Thompson and J. E. Fromer (eds), Resiliency in Ethnic Minority Families, Vol I: Native and Immigrant American Families, Centre for Excellence in Family Studies, University of Wisconsin, Maddison, Wisconsin. 